\title{
Comunicação visual e imaginários culturais iconográficos do contemporâneo
}

\author{
Maria Beatriz Furtado Rahde ${ }^{1}$ \\ PUC- RS \\ frahde@portoweb.com.br
}

\begin{abstract}
Resumo: Este texto procura estabelecer algumas considerações sobre a comunicação visual na cultura humana e a busca por novos significados simbólicos, refletindo sobre os imaginários sociais, culturais e estéticos, que vêm perpassando as manifestações iconográficas do contemporâneo.
\end{abstract}

Palavras-chave: Cultura contemporânea, Imagem, Estética

Abstract: This text tries to establish a few considerations about visual communication in human culture and the search for new symbolic meanings, reflecting on social, cultural, and aesthetic imaginary, which have been expressed through iconographic manifestations

of contemporaneity.

Key-words: Contemporary culture, Image, Aesthetic

Résumé: Ce texte vise établir quelques considerations sur la communication visuelle de la culture humaine en cherchent par ses nouvelles significations symboliques, bien comme réflechir sur l'imaginaire social, culturel et esthétique qui passent au long de les manifestations iconographiques du contemporain.

Mots-Clés : Culture contemporain-Image - Esthétique.

Resumen: Este texto procura estabelecer algunas consideraciones sobre la comunicación visual de la cultura humana y de sus nuevas significaciones simbolicas, asi como busca reflectir sobre el imaginario social, cultural y estetico qui perpasan las manifestaciones iconograficas de la contemporaneidad.

Palabras-llave: Cultura contemporárea-Imagen - Estetica

\footnotetext{
${ }^{1}$ Dra em Educação FACED/PUCRS. Profa. Titular da Pontifícia Universidade Católica do Rio Grande do Sul (PPGCom/ FAMECOS/PUCRS ). Linha de Pesquisa: Cultura Midiática e Tecnologias do Imaginário (CMTI).
} 


\section{Introdução}

A produção imagística do homem, mais remota e tão importante quanto o universo das palavras, sempre se constituiu em forma de comunicação e cultura, desde a Era Primitiva até a contemporaneidade, quando o homem criou, fabricou e estabeleceu símbolos e formas que deram sentido à sua existência. Assim, diz Duarte Jr. (2002) , a cultura inicia com o aparecimento do homem em nosso Planeta.

Retomando passados distantes e aproximados, constatamos, neste início de milênio, que as mais variadas tendências de representações visuais se entrelaçam. As imagens criadas pela modernidade, por exemplo, buscaram o novo, que teria de surpreender até o inovador: uma imagem plena de ressonâncias e suavidades, não representava mais valor algum. Opondo-se ao Classicismo, ao Romantismo, ao Realismo, ao apego a todo e qualquer valor tradicional, as idéias progressistas da modernidade identificaram-se muitas vezes com o racional, com renovações da produção iconográfica, seja na pintura, na escultura assim como na fotografia e na própria paisagem urbana

Foi Jean François-Lyotard ( 1994) quem introduziu, ainda nos anos setenta, a idéia de uma nova condição, além da modernidade, como necessidade de superação desta, principalmente no que tange à crença na razão e nas ciências, considerando o modernismo como o responsável pela falta de liberdade e emancipação humanas. E esta liberdade só poderia ser alcançada por meio da valorização de uma arte híbrida, dos sentimentos, do imaginário.

O contemporâneo que estamos vivenciando, ao contrário de momentos anteriores, vem aceitando as mais diversas mudanças, nada negando mas questionando e agregando em si variados estilos imagísticos, compondo-se, assim, de muitos fractais, de hibridações de variadas técnicas gráfico/plásticas. Isso revela uma nova forma de comunicação iconográfica, perpassada por imaginários culturais de uma sociedade em mutação o que, por suposto, vem modificando significados sociais e culturais. 


\section{Culturas, imagens, modernidade}

A imagem sempre revelou mensagens, a princípio envolta em mistérios rituais, com seu alfabeto transmissor e produtor de comunicação, desde a PréHistória, quando o homem narrou seu cotidiano nos símbolos pictóricos das cavernas. O mito, o imaginário, o ritual, permearam estas primeiras representações visuais e o homem primitivo simulou formas que desejava materializar, pondera Malrieu (1996).

Como fenômeno social e cultural, a comunicação iconográfica foi se desenvolvendo numa troca de mensagens entre passado e futuro, e este último foi capaz de decodificar os símbolos, adquirindo o conhecimento e a compreensão de um imaginário ancestral.

Certamente surgida muito antes da articulação das palavras, a imagem vem se constituindo na forma viva que perpassou todas as civilizações humanas: Da Era Primitiva ao mundo antigo, da Antigüidade Clássica ao mundo medieval, do Renascimento ao Barroco e deste à Arte Moderna, chegando à contemporaneidade que estamos vivenciando. Assim, a comunicação imagística permanece representando papel relevante na trajetória social e cultural da humanidade, fonte de influência na comunicação estética e epistemológica.

Desde seu aparecimento, a iconografia guarda no seu âmago um significativo envolvimento cultural que vai da ideologia à estética, da política à sociologia, da obra aurática à comunicação visual de massa, num processo contínuo de transformação de consciências. Provavelmente foi Platão (1947) quem deu a conhecer um dos mais antigos conceitos de imagens ao chamá-las de sombras, reflexos nas águas ou ainda uma espécie de reprodução das formas que aparecem na superfície de objetos polidos e brilhantes, assim como noutras representações visuais nesse gênero. Essas ponderações do filósofo constituiam-se numa visão das imagens como projeção do existente, seja nas sombras, seja no que podemos chamar "espelho" de um objeto ou de uma forma da natureza.

No entanto, a imagem não se restringe apenas à visão de reprodutibilidade da natureza, mas de um real intrínseco, de simulacros e de simulações (Baudrillard, 
1991), em que o imaginário e o imaterial estão inseridos na sua produção, na sua participação na sociedade e na cultura, assim como na sua fruição.

Na modernidade a máquina fotográfica tornou a imagem mais próxima do indivíduo do que a pintura: a imagem fabricada por um novo olhar perceptivo, aliada ao olhar mecânico do aparelho que captava imagens, rememorou e remeteu o cotidiano a um novo mundo permeado pelo raciocínio e pela imaginação, que o fotógrafo passou a idealizar. Isto permitiu e ofereceu outras possibilidades de visualizações imagísticas, que estavam ao alcance de todos.

Tornando-se base para a criação de novas imagens, a fotografia contribuiu de maneira indiscutível para a produção imagística de mundos também invisíveis, tornando possível uma outra visualidade. A observação e os estudos do iconográfico passaram a pertencer tanto ao espectador/produtor/artista, como ao cientista. A invenção da radiografia, por exemplo, revelou o universo complexo do interior dos corpos, possibilitando à ciência uma visualização das novas formas, por meio de técnicas de imagens impressas em películas sensíveis aos raios $\mathrm{x}$.

O advento da fotografia sacudiu os meios artísticos. Durante anos, Emerson, um pintor inglês do século XIX, abandonou a pintura temporariamente, em favor da fotografia. Como fotógrafo popular da época, proferiu diversas conferências sobre a fotografia como arte, apesar das controvérsias existentes a este respeito: Os artistas plásticos negavam tanto seu processo quanto seu produto final como obra de arte, uma vez que ela era reprodutível, perdendo a aura de obra única. No entanto é impossível negar que a fotografia exerceu uma profunda influência na visão do artista plástico, mudando também a visão que as pessoas possuíam das obras plásticas,ao democratizar as imagens pela sua reprodução.

O surgimento do Impressionismo, utilizando a cor luminosa, que se estendia às próprias sombras dos objetos, com a linha de contorno das imagens desmanchada, assim como novas formas de pincelar foi uma certa reação contra a perfeição das imagens fotográficas. Entretanto, é curioso registrar que, em alguns casos, os pintores impressionistas copiaram abertamente suas composições visuais, das imagens fotografadas. Foi o caso de Paul Gauguin, quando de sua fase no Tahiti. Gauguin se utilizou de fotografias impressas nos cartões postais e, partindo delas, 
elaborou diversas composições de suas obras. Georges Seurat (1859-1891), com seu estilo pontilhista chegou a dizer que criara esta técnica, observando fotografias granuladas de sua época. Como um dos fundadores do Neoimpressionismo racionalizou a técnica da pincelada, com métodos divisionistas, mediante o pontilhismo (Vieira da Cunha, 1997).

Pouco a pouco tornou-se decisivo o papel da fotografia nas artes plásticas, e a pintura do séc. XIX se serviu da nova onda para a representação do nu, como nas obras de Courbet e Rodin, diz o artista plástico Vieira da Cunha (1997). No seu artigo "A mais humilde servidora da arte", o autor afirma que a grande obra de Courbet , "A origem da vida" foi resultado da mecânica da máquina fotográfica e da reação química na revelação do negativo.

Em 1998, a Biblioteca Nacional da França realizou uma exposição denominada "A arte do nu no século XIX", em que, ao lado das imagens dos mestres foram mostradas também obras fotográficas, fonte de inspiração dos temas plásticos. O escultor Rodin, por exemplo, manteve grande número de imagens fotográficas no seu atelier, exibindo fotos de modelos nus, que teriam posado para fotógrafos da época, contribuindo, assim, para as soluções das muitas posturas do corpo humano realizadas pelo escultor (Vieira da Cunha, 1997).

No período da modernidade, as artes plásticas e a fotografia representaram imagens que caminhavam lado a lado e, de certa maneira, foi a fotografia, vista como meio de comunicação visual, como nova curiosidade da invenção humana, que apresentou ao povo europeu e americano a chamada "arte moderna". Foi desta forma que a obra de arte tornou-se conhecida fora dos museus, das galerias, das exposições, ao ser reproduzida em livros, enciclopédias, o que possibilitou o conhecimento das produções artísticas pelo público em geral.

Chamou-se Pictorialismo um movimento fotográfico que perdurou até 1910 e foi uma tentativa mais séria dos fotógrafos para sua aproximação com a pintura. Tendo sido um dos pontos altos da história da fotografia das imagens de arte, o Pictorialismo enfrentou as maiores dificuldades técnicas na impressão de suas imagens em chapas de vidro, que, após trabalhadas e retocadas manualmente, eram copiadas em papel fotográfico. A própria cópia, também retocada à mão, produzia um 
resultado final para ser datado e assinado; o negativo em vidro era destruído, de forma que a finalização imagística continuasse única. Persistia, assim, o conceito de obra aurática, sacralizada para que a reprodução das imagens se tornasse impossível.

\section{Culturas, imagens, contemporaneidade}

O conceito de obra de arte aurática tem sido questionado desde o final dos anos cinqüenta e talvez tenha sido o pintor norte-americano, Robert Rauschenberg, quem tornou a pintura uma clara imagem de comunicação no século XX. Ao lado de Man Ray , o mais jovem componente do movimento dadaísta de Nova York, Rauschenberg passou a empregar " processos de collage fotográfico e serigráfico, produzindo impressões diretas de objetos imagísticos sobre placas sensibilizadas, cujos efeitos não são definíveis" (Thomas, 1994, p. 102). Ainda que a idéia não fosse totalmente nova, a grande novidade de Rauschenberg foi sua conversão às fotocollages, trabalhando suas pinturas a óleo juntamente com objetos figurativos de consumo.

As imagens transformaram-se em verdadeiras barroquizações: Robert Rauschenberg reconstrói um quadro de Rubens por meio de impressão serigráfica, utilizando collages de muitos temas sobre uma reprodução de "Vênus no banho" do pintor barroco: pintura, serigrafia, fotografia, criam uma hibridação técnica nesta obra de 1964, considerada por muitos teóricos, como a grande manifestação da pintura contemporânea.

A colagem de papéis, jornais, objetos sobre tela data do início do século XX, com Picasso e Braque, entre 1909 e 1912, numa época em que a hibridação de materiais só existia no artesanato ou na arte popular. Trazendo maior liberdade aos artistas, cujos estilos eram bem definidos na arte moderna, a collage passou a fazer parte das telas de Picasso e Braque, assim como vai gradualmente aparecendo nas obras de Max Ernst, comprovando que idéias prospectivas já se manifestavam nas artes plásticas, muito antes do surgimento de um conceito teórico de uma nova representação visual, além da modernidade (Thomas, 1994).

Com o surgimento da Pop-Art, ao redor dos anos sessenta, que integrava imagens populares de propaganda e de consumo junto à pintura e à serigrafia em grandes telas, esta montagem de temas e materiais evoluiu para a técnica pictórica 
denominada combine-painting, com a introdução de objetos diversos nas obras plásticas. Foram estas novas possibilidades de colagem que Robert Rauschenberg introduziu no seu trabalho, juntamente com outros artistas, como Andy Warhol, levando a arte plástica de elite a hibridar-se com a arte popular. Provavelmente foi o período de maior comunicação gráfico/plástico que este movimento introduziu na pintura, com objetos comuns de consumo dos mass media. Outro exemplo é o do inglês David Hokney, exímio desenhista e consagrado pintor de fontes e piscinas, que utiliza também a fotografia como base de suas obras reinventadas, opinativas e críticas de uma Califórnia repleta de riquezas, grandes jatos d'água e gramados. A arte, assim , tornou-se cada vez mais independente dos estilos definidos, criando novas formas de expressão que buscaram uma aproximação e um contato maiores com o popular e cada vez mais firmando-se como meio visual de comunicação.

Buscando questionamentos que a nova visualidade vem impondo ao espírito inconstande da humanidade no final do século XX e início do século XXI, as diversas formas de representação das imagens estão cada vez mais unidas e entrelaçadas em manifestações mistas de expressividade. A expressão imagística ressurge com outras linguagens nesta nova cultura, sustentando a experimentação e a combinação da pintura com o desenho, com a fotografia, com objetos, com novas tecnologias do imaginário, interpretando as formas e criando uma nova e ampla " bagagem icônica, da qual podemos nos valer para as nossas futuras imagens a serem reveladas e elevadas ao papel de obras de arte autônoma". (Dorfles, 1992, p. 223)

Pregando a complexidade, o híbrido, a desconstrução, as idéias e representações do contemporâneo, essas imagens concebem as mais amplas polivalências da percepção e do imaginário humanos. A procura da liberdade na construção e criação das imagens, não segue uma obediência irrestrita às leis e à razão, como aconteceu em alguns movimentos modernistas, mas caminha noutras direções, numa união entre conhecimento e imaginário, que traduz, reinterpreta e, por isso mesmo, transforma conceitos estéticos em novas formulações imagísticas.

Na paisagem urbana das grandes cidades também é possível perceber uma visualidade irreal, por vezes, que vem alimentando o imaginário dos habitantes. Referindo-se especificamente a Las Vegas, nos Estados Unidos, Venturi et al (1998) põem em questão a nossa forma de visualizar o urbano. A cidade referida valoriza o 
ecletismo, combinando os mais diversos estilos e seus hotéis temáticos apresentam o pluralismo e a colagem que vem caracterizando o contemporâneo, numa polissemia contraditória e complexa, rejeitando a unidade arquitetônica em favor da diversidade. Como sistema de comunicação visual e cultural, os símbolos encontramse no espaço da cidade, tais como réplicas quase perfeitas de caravelas do século XVIII, lado a lado com edifícios/cópia do Palácio dos Dodges de Veneza, ou na visualidade do Excalibur Hotel, quando passamos a ser integrantes da Camelot do rei Arthur. Na reconstrução do Grande Canal de Veneza percebe-se a cultura dos anos cinqüenta, quando jatos d'água movimentam-se como passos de ballet, ao som do clássico musical hollywoodiano Cantando na Chuva, tudo isso mesclado à idéia de uma Sinfonia de Paris, diante da proximidade de uma réplica da Torre Eiffel .É uma realidade oriunda do imaginário, comunicando espetáculos simulados.

Nas ruas fechadas de Las Vegas, como a Freemont Street, com cinco boxes cobertos de grandes cúpulas, o imaginário construído pelos mitos, fantasias e mundos fantásticos é projetado no espaço, resgatando uma irrealidade onírica, que proporciona a vivência dos mais remotos sonhos, a cada meia hora. Das cavernas às naves espaciais, das luzes e projeções a laser, Las Vegas representa a espetacularização do espetáculo híbrido dessa visualidade contemporânea como simulacros da realidade

Ao abordar as questões dos simulacros e da simulação Baudrillard (1991) refere sobre a geração de realidades sem qualquer precisão na exposição de algum fato, em que se utilizam modelos do real. Essa reflexão vai ao encontro da visualidade urbana de Las Vegas, onde tudo se constitui em simulações da realidade.

Mas não precisamos sair do Brasil para verificar que essas hibridações arquitetônico/urbanas também se verificam nos grandes estados do País: Os Shoppings Centers retratam uma espécie de architecture-collé, que se expande em nossa cultura globalizada, tornando-se exemplo internacional destas hibridações; neles vemos colunas dóricas, jônicas, usadas pelos gregos na Antigüidade, juntamente com estruturas metálicas, vidrarias, decorações florais e vegetais, pisos de mármore ou de granito polido, lado a lado com paredes de tijolo à vista. Provavelmente, no futuro, esses shoppings serão os verdadeiros museus criados no século XX. 
Convivemos, então, diariamente com essa cultura visual híbrida, nós a aceitamos e, muitas vezes, não percebemos que essas mestiçagens comunicam visualmente o que está ao nosso redor, e também no interior de nós mesmos, pois nossa forma de ver e de apreender o visualizado está se modificando. É possível afirmar que nossos valores, nossas crenças podem ter permanecido, mas esses valores e crenças têm sido re-lidos, re-estruturados, decodificados para uma interação maior com o mundo contemporâneo no qual estamos submersos.

As diversas imagens que nos cercam, sejam elas pinturas, fotografias, arquitetura tendem mais à ambigüidade e à indeterminação, e essas manifestações visuais estão beirando à efemeridade, nosso mundo está fragmentado, há maiores imperfeições do que a busca da perfeição que a modernidade proclamava. As tendências de beleza deram lugar aos produtos da indústria cultural e a ironia está por toda a parte. É uma nova cultura que foi surgindo e com a qual convivemos num prazer estético transformado.

Venturi et al (1998) ainda referem que trabalha-se com "a analogia, o símbolo e a imagem e, ainda que [se afirme] rechaçar toda a determinação das formas que não seja a necessidade estrutural [...] obtém-se idéias, analogias e estímulos de imagens inesperadas” (p. 23). Citando Henri Bergson, Venturi et al. (1998), ainda consideram que a desordem é uma espécie de ordem que não conseguimos ver. Talvez a vejamos com a imaginação, pois é através desse imaginário, dessas fantasias, desse jogo com as formas e elementos, que o sujeito "transcende a imediatidade das coisas e projeta o que ainda não existe" (Duarte Jr, 2002, p. 51). É pela cultura, pois, que o sujeito concretiza seus valores, diz ainda o autor e prossegue:

A criação da cultura é, conseqüentemente, um ato da imaginação humana. É um ato de jogar com os dados do mundo material para construir uma ordem e um sentido [...] No jogo é estruturada uma certa ordem e equilíbrio[...] permitindo que o homem se envolva numa ação prazerosa por si própria (Duarte Jr, 2002, pp 51-52).

Nossa maneira de ver está em mutação, mesmo sem que o percebamos; convivemos com as mais diversificadas e ambíguas formas e iconografias, assim como com o mundo híbrido que nos cerca; formamos imagens mentais, imaginárias ou reais com outras conotações, num eterno jogo de novas visualidades, envolvido em 
novas culturas que assolam nosso imaginário e que estamos assimilando de forma aparentemente natural. Sobre esse aspecto é preciso admitir que em nossa cultura globalizada

estão ocorrendo mudanças significativas e que muitas das antigas teorias e categorias modernas já não conseguem descrever adequadamente a cultura, a política, e a sociedade contemporâneas[...] Por conseguinte [...] estamos vivendo entre uma era moderna em envelhecimento e uma nova era [...] que precisa ser adequadamente conceituada, diagramada, mapeada (Kellner, 2001, p. 53).

Se a cultura se constitui num processo de estabelecer a ordem, como refere Bauman (1998), questiona-se se a cultura do contemporâneo mantém essa preocupação ou busca na aparente desordem uma outra harmonia ainda não mapeada, como pondera Kellner (2001), na busca de uma nova conceituação, de novos significados estéticos ou mesmo simbólicos, que possam traduzir esse momento contemporâneo que estamos vivenciando.

Observando a iconografia assim como a paisagem urbana contemporâneas que nos cercam podemos perceber a ação do sujeito numa aceitação da mestiçagem de estilos e de formas, o que não era possível de conceber no conceito de formas puras, claras e estruturadas da modernidade. A idéia do less is more parece estar desaparecendo e o excesso, a ambigüidade, a polivalência estão em crescimento no momento vivenciado, em que o sujeito está construindo uma outra realidade híbrida, com a qual parece encontrar novos e maiores significados culturais. Se o sujeito é um ser de símbolos que constrói culturas e as vivencia, é no simbólico que podem ser encontrados os mitos, os rituais, as fantasias, que fazem parte do imaginário cultural. E é essa cultura que está sendo alterada em seu processo de mutações, de misturas, reconstruindo o universo com outra visualidade.

Ao verificar que, aparentemente, o sujeito do contemporâneo tudo vem aceitando em nome dessas hibridações estilísticas, podemos dizer que o que antes era apenas lógico está cada vez mais unido ao sentimento, às crenças, às percepções, às emoções de um imaginário cultural que nos rege, uma vez que as culturas midiáticas estão dominando o mundo de hoje, diz Kellner (2001). Para tanto, prossegue o autor, é preciso decodificar e compreender essas novas culturas que nos apresentam outros modelos visuais que vêm até como substitutos para "a família, a escola, a Igreja como 
árbitros de gosto, valor e pensamento, produzindo novos modelos de identificação e imagens vibrantes de estilo, moda e comportamento" (Kellner, 2001, p. 27). Tudo isso é regido por um imaginário que se propaga rapidamente via satélite e certamente é pelo imaginário que fugimos do nosso próprio eu, buscando novas relações universais dos nossos afetos, das nossas emoções, que são expressos imagisticamente e de maneira simbólica nestes nossos outros eus, plurais, complexos e sensíveis, experimentando e estabelecendo novas configurações, num jogo de acasos.

É desta forma que a imagem não mais duplicou fielmente a realidade, refere Maffesoli (1995) , ou tampouco o reflexo da realidade: ela vem se tornando um símbolo ou ainda o desvelamento de novas formas a serem exploradas.

O imaginário é, portanto e também, uma tentativa de mudança, consciente ou não, reconstruindo formulas anteriores, interrogando e apresentando outras soluções estéticas numa reunificação de idéias formais para a convergência da pluralidade, quando expresso em manifestações iconográficas arrojadas, seja por meio de um quadro, de uma fotografia, de uma collage, de uma construção arquitetônica diferenciada do convencional.

Sem renunciar às anteriores visualidade imagísticas, mas incorporando-as às novas tecnologias e às novas formas de criar, as imagens que vêm compondo o imaginário do momento contemporâneo vivenciado tornam-se reinvenções híbridas, transformadas e relidas em novos esquemas simbólicos. Se essas imagens são sedutoras e persuasivas para um número significativo de sujeitos que as incorporam causam, muitas vezes, impactos visuais no espectador que não as assimilou. No entanto, esse novo contexto necessita de discussão e de decodificação, o que não significa uma aceitação desses novos signos visuais, mas é relevante a percepção de sua existência, a avaliação do seu conteúdo simbólico para pesquisa e busca de dados mais específicos.

\section{Considerações finais}

As mudanças ocorridas no mundo moderno desde os anos cinqüenta, até o momento demonstram o quanto as sociedades vêm encontrando novas formas culturais pelo imaginário tecnológico , criando uma outra sociedade em que " os estudos culturais podem desempenhar importante papel na elucidação das alterações 
que têm ocorrido...” (Kellner, 2001, p 29). A compreensão cultural estética está na dependência também de nosso auto-conhecimento e, se ainda pudermos cultivar uma harmonia estética interior, ela certamente, nos irá conduzir à apropriação de uma percepção maior do mundo, num processo de reconhecimento, de compreensão e de interpretação. É por essa razão que acreditamos ser absolutamente necessário o desenvolvimento harmônico interior do ser humano, da percepção de si mesmo para o desenvolvimento da sensibilidade, o desenvolvimento da personalidade, da liberdade criadora e de um outro olhar sobre o novo que se configura.

A desconstrução das imagens e das formas vem conduzindo a novas decodificações para a construção iconográfica, criando outros cânones imagísticos explícitos visualmente e implícitos no seu conteúdo, para serem refletidos no mundo hoje, numa outra visão psicossocial: a imagem do século XXI incorpora a cultura desta contemporaneidade, das novas possibilidades tecnológicas, que o contemporâneo está oferecendo, buscando novos espaços como linguagem, em que mundos imaginários estão sendo revelados numa outra estética visual. O encontro dessa nova estética no mundo de hoje parece fundamental: Se não encontramos a perfeição na representação visual do contemporâneo, como era a exigência dos cânones da modernidade, o imaginário da cultura ocidental de hoje, incluso e mais liberto, aceita imperfeições, muitas vezes propositais, pois que elas podem ampliar significações das representações visuais. Conforme Bauman (1998), essa parece ser a busca da liberdade, na construção e na recriação das imagens, que vem encontrando novos caminhos de expressão em novos imaginários tecnológicos, os quais estão traduzindo, reinterpretando e, por isso mesmo, transformando conceitos estéticos em novas possibilidades imagísticas que estão perpassando a cultura visual contemporânea. 


\section{Referências Bibliográficas}

BAUDRILLARD, Jean. Simulacros e simulação.Lisboa: Relógio d'Água , 1991.

BAUMAN, Zygmunt. O mal-estar da pós-modernidade. Rio de Janeiro: Zahar, 1998.

COELHO NETTO, José Teixeira. Moderno Pós-moderno: Modos \& Versões. São Paulo: Iluminuras, 1995

DORFLES, Gillo. O devir das artes São Paulo: Martins Fontes, 1992.

DUARTE JR. João Francisco. Fundamentos estéticos da educação. Campinas, SP: Papirus, 2002.

GERVEREAU, Laurent. Voir, comprendre, analyser les images. Paris: La Decouverte, 2000

KELLNER, Douglas. A cultura da mídia. Bauru, SP: EDUSC, 2001.

LYOTARD, Jean-François. La condicion postmoderna. Madrid: Catedra, 1994.

MAFFESOLI, Michel. A contemplação do mundo. Porto Alegre: Artes e Ofícios, 1995.

MALRIEU, Philippe. A construção do imaginário. Lisboa: Instituto Piaget, 1996.

PLATÃO. La République. Paris: Les Belles Letres, 1947.

THOMAS, Karin. Hasta hoy. Estilos de las artes plasticas em el siglo XX. Barcelona:

Ediciones del Serbal, 1994.

VENTURI, Robert et al. Aprendiendo de Las Vegas. Barcelona: Gustavo Gili, 1998.

VIEIRA DA CUNHA, Eduardo. A mais humilde servidora da arte. Porto Alegre: Zero Hora, Caderno de Cultura, 20, dez., 1997 